\title{
Concepção de Criança na Pós-Modernidade
}

Child's conception in the new modernity

Adelma Pimentel \&

Lucivaldo da

Silva Araújo

Universidade

Federal do Pará

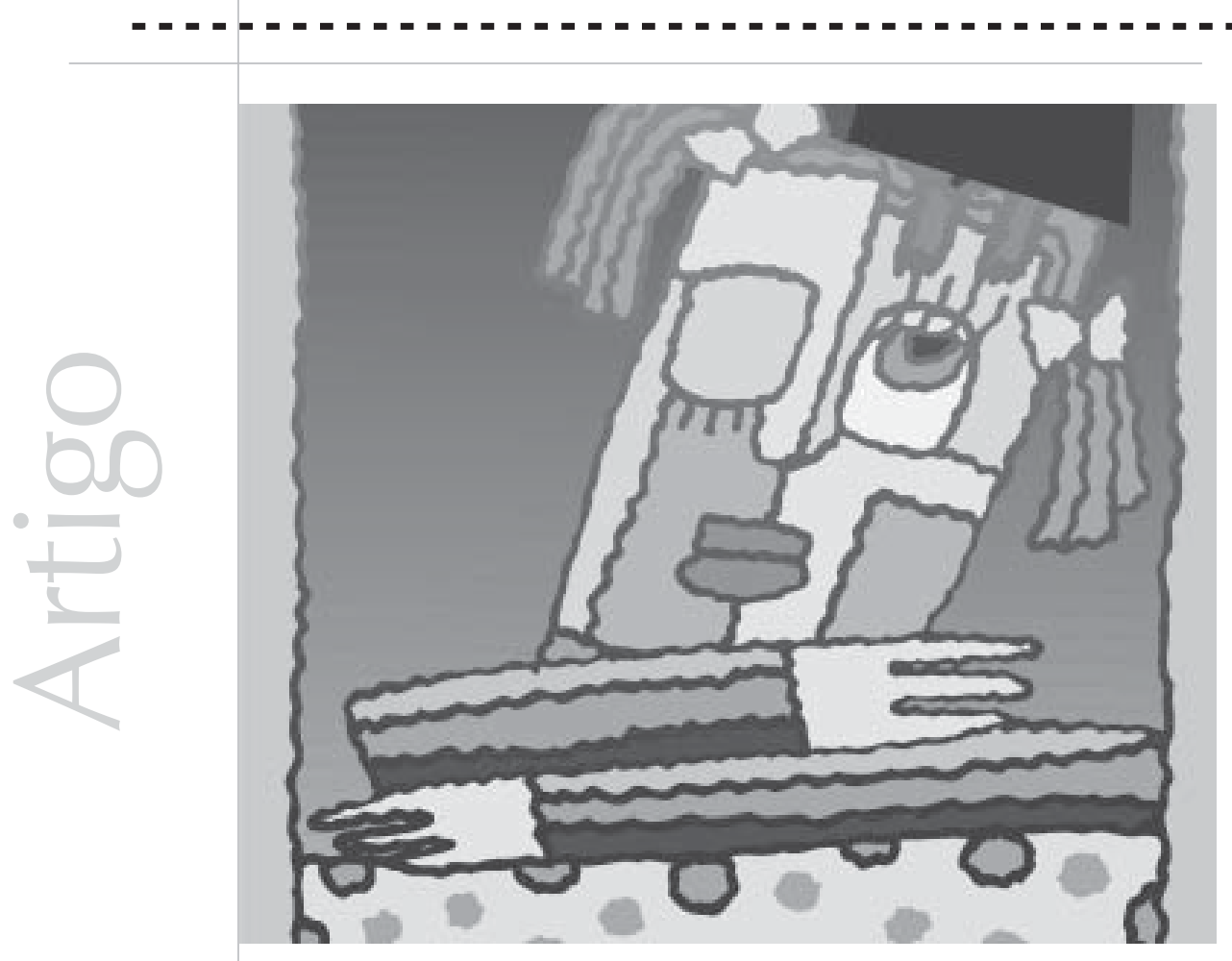




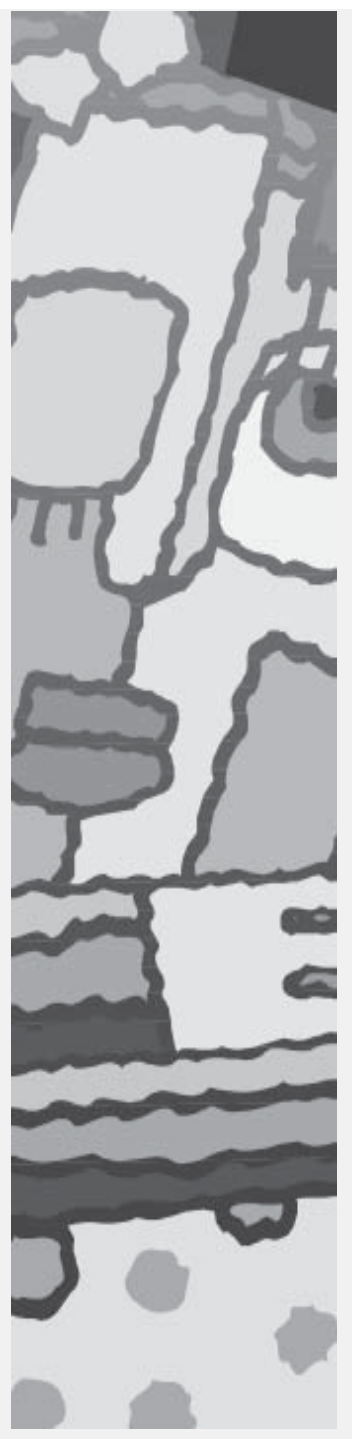

Resumo: O artigo apresenta uma perspectiva sintética da concepção de criança, pontuando questões relacionadas à pós-modernidade e ao problema da violência sexual intrafamiliar, o que faz parte da revisão bibliográfica para a elaboração de dissertação do Mestrado em Psicologia Clínica e Social da UFPA. As reflexões são articuladas através dos pontos de vista da Psicologia e da terapia ocupacional, pois a primeira é a base do nosso mestrado, e a segunda, do campo de atuação. O pensamento pós-moderno valoriza o singular e o idiossincrático, assim, apreender o discurso sobre a criança nos remete à importância de compreender o que elas próprias pensam e sentem sobre a sua condição infantil. A Psicologia da qual nos valemos oferece, para as análises, o conceito de nutrição psicológica, que diz respeito ao provimento, pelos cuidadores, de alimentos positivos capazes de permitir à criança desenvolver-se de modo criativo e saudável; além desse conceito, a terapia ocupacional apresenta o de atividades expressivas.

Palavras-chave: criança, pós-modernidade, violência sexual intrafamiliar.

Abstract: The article presents a synthetic perspective of the child's conception, punctuating subjects related to the new-modernity and to the problem of the sexual violence inside the family, what is part of the bibliographical revision for the elaboration of the Master's degree work in Psychology by the UFPA. The reflections are articulated through the point of view of Psychology and of occupational therapy, because the first is the base of our master's degree paper and the second is our field of work. The new-modern thought values the singular and the idiosyncratic; so learning about the speech of the child shows us the importance of understanding what children think and feel about their infantile condition. The Psychology we based on offers for the analyses the concept of psychological nutrition, related to the offers the caretakers make of positive nutrition, which allows the child to grow in a creative and healthy way; besides this, occupational therapy presents the concept of expressive activities.

Key words: child, new-modernity, violence sexual inside the family.

Investigamos, em nosso mestrado em Psicologia, a problemática da violência sexual intrafamiliar praticada contra crianças, logo, refletiremos a questão através das contribuições teóricas da terapia ocupacional acerca das atividades expressivas do homem e da Psicologia fenomenológica existencial, via conceito de nutrição psicológica.

A compreensão e experiência do que éser criança modifica-se cronologicamente, de sociedade em sociedade e dentro da mesma sociedade. Derivado do latim creantia, criantia, o termo criança, assim como o discurso acerca de sua significação, tem sofrido influências do momento histórico, da cultura ou da relação que esses entes estabelecem com aqueles que os rodeiam; entretanto, o significado descrito em um dicionário permanece definindo a criança como "um ser humano com pouca idade, menino ou menina; pessoa ingênua, infantil" (Ferreira, 1999). Por muito tempo, essa foi, ou ainda é, a visão acerca da criança.

A etimologia de infância deriva de "infante", do latim "infans", que significa incapaz de falar. Ora, mais ou menos aos dois ou três anos de idade, a criança já domina um vasto repertório lingüístico, e sua fala já se transformou em um instrumento de comunicação, o que nos permite concluir a 
falácia contida na raiz etimológica (Ministério da Saúde, 2001).

A infância não pode ser entendida apenas como mais um período na vida do indivíduo em formação, mas como um momento construído no contexto de cada grupo social e que assume "naturezas" que variam segundo épocas e condições históricas diferentes (Castro, 2002), daí a importância de se denotar com clareza um corte entre ser criança à luz da construção social e ser apenas criança enquanto condição de maturação biológica, pois, segundo Oliveira, apud Boarini e Borges (1996, p. 03), "a existência desse corte determina a criança com o gozo das condições para viver de determinada forma seu tempo de criança e crianças excluídas dessa condição."

A mesma autora ainda pontua que, se não considerarmos essa ruptura, a infância - enquanto construção histórica - perde sua concretude e torna-se "uma mistificação, uma ideologia, um dado eterno, natural, próprio da espécie, como costuma perpassar o senso comum" (p. 92). Portanto, estender esse sentimento de infância a todas as crianças é tratar a infância como um dado universal, a-histórico e, portanto, ideologizado.

Heyhood (2004, p. 22) reitera as observações de Oliveira quando afirma que a infância, obviamente, é uma abstração que se refere a uma determinada etapa da vida, diferentemente do grupo de pessoas sugerido pela palavra criança.

Embora circule socialmente o saber que a criança viva é diferente da criança teorizada, ainda podemos facilmente encontrar, no repertório lingüístico de muitas pessoas, a idéia de semelhança entre as mesmas, expressa nas falas dos adultos como: "Não seja criança!", "Vocêestá sendo infanti!!", "Ao agir assim, você parece uma criança!", etc. São muitas as situações do cotidiano em que, mesmo sem perceber, depositamos sobre a criança o estigma de incapaz, dependente, inconseqüente e não habilitada a emitir opiniões válidas.

As pesquisas realizadas por Pimentel (2003/2005) e pelos integrantes do NUFEN (Núcleo de
Pesquisas Fenomenológicas)/Laboratório do Desenvolvimento Humano tem procurado valorizar a fala da criança, respeitando-a como indivíduo capaz e sujeito de sua própria realidade. Neste texto, apresentaremos o panorama sucinto de algumas teses contidas no discurso pósmoderno sobre a criança.

\section{A concepção de ciência na pós- modernidade}

São diversas as correntes que descrevem a etapa do pensamento científico vigente. Considerando essa diversidade, antes de nos determos no exame da concepção pós-moderna de criança, apresentaremos nossa compreensão acerca da pós-modernidade, baseando-nos nas obras de Bello (2004) e Stein (2001) para caracterizar o que os autores denominam "crise da modernidade."

Bello (2004, p. 16) chama de Idade Moderna ${ }^{1}$ o período que começa a partir dos séculos XV e $X V I$ e que, por convenção, segundo o autor, tem seu fim dado na metade do século XIX. Nas duas últimas décadas, pós-modernidade tornou-se um conceito relacionado a uma lenta transformação cultural nas sociedades ocidentais, que não deve ser entendida de forma exagerada, como alguns consideram, associando-a a transformações globais de paradigmas nas ordens social, cultural e econômica (Harvey, 2004).

A natureza e a profundidade dessas transformações são discutíveis, mas os pesquisadores concordam que estas são significantes, nos campos da sensibilidade, nas práticas e nas formações discursivas, que distinguem um conjunto pós-moderno de pressupostos, experiências e proposições do período findo antecedente (modernidade) (idem).

Stein (2001, p.21)), comentando a questão, afirma que:"O fim da modernidade é o momento em que não foi mais possível sustentarmos que é possível, através de um único sistema filosófico, dar explicações que tenham eficácia em todos os domínios do saber humano: em nível cognitivo, em nível de conhecimento, em nível prático, em 
nível moral e também em nível subjetivo, em nível artístico, etc. No momento em que perdemos essa unidade de um sistema, ou a possibilidade de haver um sistema filosófico que explique as diversas regiões fundamentais do saber e do convívio humano, nesse momento, chegamos ao fim da modernidade".

O autor observa que a desconstrução dos paradigmas não permite aos pesquisadores manter a fé na ciência e na tecnologia enquanto ferramentas reveladoras da verdade (idem). Essa é outra característica da pós-modernidade.

Concordamos com Stein (2001) quando este destaca que estamos vivendo um período de transição, em que somos seres de dois mundos, do não mais e do ainda não. Todavia, em algumas áreas mais específicas do conhecimento, como a das ciências sociais, é possível visualizarmos, de forma bem mais definida, esse momento de mudança. Vejamos algumas nuanças da Psicologia e a terapia ocupacional.

\section{A Psicologia e a terapia ocupacional}

No campo da Psicologia, a separação desta da Filosofia conduziu à sistematização de teorias e práticas afinadas com a ênfase iluminista no progresso e na tecnologia. O projeto científico moderno pautou-se pelos parâmetros de métodos lógicos e empíricos, que permitiam descobrir leis gerais para o comportamento. A correspondência com a realidade, criteriosamente observada e confirmada pela replicação dos resultados de observações científicas obtidos, também eram critérios do projeto da ciência Psicologia.

Na pós-modernidade, as diretrizes para a ciência reformularam os temas e as práticas psicológicas valorizando o singular, o idiossincrático e o contextualmente situado, em vez das leis gerais. Nesse bojo, constatamos o fortalecimento e a visibilidade das psicologias de base fenomenológica existencial, dentre elas, a Gestaltterapia, cujos autores propõem as teses do metabolismo dental (Perls, 1975) e da nutrição psicológica (Pimentel, 2005) para entender o desenvolvimento emocional e social de crianças.
Perls (1975) considera a nutrição psicológica um processo que recorre à utilização dos dentes e à agressividade positiva, que, durante o desenvolvimento infantil, é de fundamental importância para a constituição de um adulto saudável. A idéia é fundamentada pela apreensão da união do físico e do mental como partes de um mesmo todo, ou seja, os processos de ambos acontecem de forma semelhante. Com isso, ele lança a analogia entre os processos de destruição do alimento orgânico como similar à destruição do alimento psicológico.

Realizando investigações empíricas junto a menores de sete a dez anos, refletimos sobre a nutrição e a metabolização dos alimentos psicológicos. O objetivo foi examinar a ação dos processos psicológicos e educativos que contribuem para a formação criativa da autoestima e do autoconceito. Uma de nossas conclusões foi identificar que, no processo de metabolização psicológica, os dentes emprestam a qualidade de suas funções às ações do Eu, contudo, as qualidades não são associadas a uma estrutura psíquica, a um órgão, como, por exemplo, a boca, responsável pela mastigação. A analogia é oferecida pelos atributos dinâmicos operacionais do sistema digestivo - modo de quebrar os alimentos em partes. Logo, para haver nutrição psicológica saudável, faz-se necessário cortar, rasgar e triturar as orientações e informações contidas nos padrões de socialização da cultura em que a criança vive e que orientam as formas de expressividade e reconhecimento do outro (Pimentel, 2003).

Do ponto de vista da terapia ocupacional, é possível afirmar que a ciência (para uns, enquanto, para outros autores, a disciplina), nascida num momento de mudanças marcantes no cenário sociopolítico mundial (após a Segunda Grande Guerra), passou e tem passado por inúmeras transformações decorrentes de sua evolução teórica e da crescente autonomia em relação às outras ciências.

Medeiros (2003, p. 29) retrata muito bem esse período pelo qual a profissão vem passando, referindo que: 
"Tomada como profissão, a prática

da terapia

ocupacional é

bastante nova,

comparada às

demais. Como

área do

conhecimento, ou

ciência, que

pretende ser, é

mais nova ainda.

Não conta com

uma tradição de

conhecimentos

próprios bem

sistematizadose,

por isso, ainda não

podeter

epistemologia

própria, como as

demais ciências.

No entanto, esse

esforço já foi

iniciado com

publicações de

trabalhos que

procuram trazer

algumas reflexões

para o debate epistemológico."

Medeiros
“Tomada como profissão, a prática da terapia ocupacional é bastante nova, comparada às demais. Como área do conhecimento, ou ciência, que pretende ser, é mais nova ainda. Não conta com uma tradição de conhecimentos próprios bem sistematizados e, por isso, ainda não pode ter epistemologia própria, como as demais ciências. No entanto, esse esforço já foi iniciado com publicações de trabalhos que procuram trazer algumas reflexões para o debate epistemológico."

Defini-la nunca foi simples. Às vezes confundida com recreação, outras vezes como passa-tempo, a terapia ocupacional tem se estabelecido, cada vez mais, como uma área do conhecimento e de prática de saúde. Como método, procura recuperar a dimensão ativa da existência humana como indicador de saúde, fazendo uso das atividades empreendidas pelo homem ao longo da história de sua humanização; enquanto ciência, pesquisa o próprio fazer, de modo a atualizar a compreensão da ação processual empregada nas intervenções do terapeuta ocupacional.

No campo das proposições pós-modernas para a produção do conhecimento, a terapia ocupacional é fruto deste "novo olhar". Tomando como instrumento de atuação o uso da atividade, "a própria profissão se configura como uma atividade eminentemente crítica do ato de fazer e, portanto, da postura do ser" (Jorge, 1995, p. 37).

A terapia ocupacional vê-se inserida ativamente na produção do conhecimento no contexto pósmoderno, pois participa, com outras profissões, de um processo de transformação nos atendimentos à saúde de modo geral, caracterizado pelo uso de atividades expressivas e criativas, associadas a abordagens psicodinâmicas e sociais (Nascimento, 1991).

A atividade representa o instrumento de atuação da terapia ocupacional, no entendimento de que esta é toda e qualquer expressão humana verbal e não verbal. Com fins terapêuticos, dentre elas, destacamos pintura, desenho, modelagem e escultura, que, mais do que as palavras, exprimem os pensamentos e sentimentos do homem
(Liberman, 1998). Assim, as atividades passam a ser percebidas enquanto processos e interpretações mediativas entre nós e os fenômenos que são construídos na comunicação, na experiência e na situação vivida segundo a história, as práticas sociais e os valores culturais que cada pessoa ou grupo social realiza de forma particular (Barros; Chirardi; Lopes, 2002).

Para focalizar a questão da violência sexual intrafamiliar, passaremos, a seguir, à abordagem do lugar social da criança.

\section{O lugar social da criança}

A visão sobre a criança e seus papéis sociais nem sempre foram os mais favoráveis às mesmas. No Brasil, desde os períodos de colonização, a organização social é marcada pela prioridade do poder dos adultos sobre as crianças.

Diferentes discursos produzidos pelo universo adulto enquadraram a criança, determinando os espaços que ela deveria freqüentar e estabelecendo os princípios norteadores do seu crescimento e educação. Paralelamente, era a rotina do mundo adulto que ordenava o cotidiano infantil, por meio de um conjunto de procedimentos e práticas aceitos como socialmente válidos (Mauad, 2004, p. 140).

Crianças e adolescentes eram tratados como objetos, considerados como indivíduos não portadores de direitos e de cidadania, entendidos como objetos que podiam ser modelados e manipulados de acordo com interesses e valores que não eram os seus (Rosa; Silva, 2004).

Andrade (1998), investigando famílias, identifica uma problemática que vem sendo mantida e sustentada por um imaginário social: pensar a criança como um "ainda não", algo que um dia se tornará sujeito (quando adulto) ou ainda uma extensão, um pedaço dos pais.

A legislação brasileira, entre as normas de Direito público, utiliza, em geral, a expressão "menor", fixando a idade de dezoito anos para o encerramento da menoridade e o alcance da plena 
capacidade. Assim, aos dezoito anos, a pessoa adquire a condição de sujeito de direitos e deveres e plena responsabilidade (Steiner, 1986).

No Direito civil, a menoridade cessa aos vinte e um anos. A lei civil confere aos menores a condição de absolutamente incapazes até os dezesseis anos e a de relativamente incapazes até os vinte e um. A legislação trabalhista considera menor o trabalhador entre doze e dezoito anos, e proíbe o menor de doze anos de trabalhar. $\mathrm{Na}$ reivindicação judicial de seus direitos, o menor deverá ser representado pelos pais, ou assistido, se maior de dezesseis anos e menor de vinte e um (idem - grifo nosso). O discurso jurídico reitera a imagem e situação da criança, perante a lei, como alguém que não tem direitos próprios e depende de seus genitores.

Áries ${ }^{2}$, apud Boarini e Borges (1996), afirma que, anteriormente à modernidade, inexistia um sentimento ou uma consciência da diferença entre o adulto e a criança. Acredita-se que não houvesse lugar para a criança nas sociedades antigas. Até o século XII, a infância era desconhecida ou não representada.

Na civilização medieval, ou até o início da época moderna, a criança passava a ser independente, a cuidar de si mesma e a freqüentar o mundo dos adultos como uma igual, pouco depois do desmame, por volta dos sete anos (Andrade, 1998). Ao longo dos séculos $X V$ e $X V I$, e, mais precisamente, durante o século XVII, foram surgindo representações de crianças. $\mathrm{O}$ retrato refletia o espaço que a criança ganhava na consciência social e o surgimento de um sentimento novo da sociedade para com ela. Anteriormente, havia algumas representações de crianças, mas com características físicas de adulto, "adultos em miniatura", identificados a santos, anjos, deuses, etc. Foi nesse século também que os retratos de família tenderam a se organizar em torno da criança, que se tornou o centro da composição. A imagem da criança celeste, angelical e endeusada foi sendo superada pela imagem da criança real, histórica, com feições determinadas, com vestimentas específicas e com uma identidade particular (Boarini e Borges, 1996).
Todavia, essa nova mentalidade diante da criança não aconteceu por obra do acaso, mas ocorreu a partir das transformações sociais inerentes ao modo de produção capitalista. Nessa nova organização social, descobre-se a criança enquanto força de trabalho. É pelo trabalho da criança, ou melhor, pela exploração dessa mão-de-obra, que a infância é reconhecida.

Ao retirar da criança seu poder de trabalho, o Estado reforça a idéia de proteção e controle da infância assim como a ideologia de que a criança pertence aos pais, cabendo a estes a principal responsabilidade sobre aquele futuro adulto. $\mathrm{A}$ criança nunca é considerada individualmente, mas é condenada a uma situação de minoridade, baseando-se em um juízo coletivo que, por sua vez, se baseia em postulados de um modelo psicológico de criança (Andrade, 1998).

O Estado, então, a partir de um interesse acentuado pela educação da criança, com o objetivo de assegurar a existência de uma população adulta saudável, adaptada e produtiva, inicia um processo de infantilização da mesma. A família deixa de ser capacitada a educar os filhos e estes passam a ser educados sob a tutela da escola. A aprendizagem tradicional foi substituída pela escola, "uma escola transformada, instrumento de disciplina severa, protegida pela Justiça e pela política" (Andrade, 1998, p. 277). A partir desse momento, a criança passa a ser considerada um ser inacabado, objeto de normas, submetida a uma hierarquia rigorosa a fim de se tornar, amanhã, um adulto completo. Passou-se a admitir que a criança não estava madura para a vida, e que era preciso submetê-la a um regime especial, a uma espécie de quarentena antes de deixá-la unir-se aos adultos.

Entender o discurso (o que se fala) e a concepção ${ }^{3}$ (o que se entende) pós-moderna sobre criança nos remete à compreensão daquilo que os adultos pensam e sentem sobre os mais jovens, já que a infância é, em grande parte, resultado das expectativas dos adultos (Andrade, 1998).

Hazeu (2004, p. 15) complementa afirmando que "ser criança é parcialmente responder pela
2 As publicações de Áries foram um marco na história dos estudos sobre a criança, porém o autor é alvo de muitas críticas, principalmente por parte de alguns historiadores que questionam seus métodos e formas de análise, mas, sem dúvida, seu olhar muito contribuiu, e ainda contribui, para o desenvolvimento de novos olhares sobre a criança.

3 "Nesse momento, pode ser útil tomarmos como referência os filósofos, ao se fazerem distinções entre um conceito e uma concepção. David Archard sugere que todas as sociedades, em todas as épocas, tiveram o conceito de infância, ou seja, a noção de que as crianças podem ser diferenciadas dos adultos de várias formas. O ponto em que elas diferem é em suas concepções de infância, as quais especificam essas formas de distinção, portanto, elas terão idéias contrastantes sobre questōes fundamentais relacionadas à duração da infância, às qualidades que diferenciam os adultos das crianças e à importância vinculada às suas diferenças" (Heywood, 2004, p. 22). 
expectativa do queéser considerado criança pelos adultos de quem ela depende biologicamente na lógica da organização da sociedade."

Do ponto de vista jurídico, a elaboração do Estatuto da Criança e do Adolescente (ECA), no seu art. $2^{\circ}$, define criança como a pessoa de até doze anos de idade incompletos, além de reconhecê-la como sujeito de direitos.

As instituições e os profissionais que atuam com a infância inicialmente interpretam a proposição "sujeito de direitos" como sujeito social, com direito à educação, saúde, profissionalização, moradia, etc. Passados os anos, e diante do não atendimento de algumas demandas sociais das crianças, e, principalmente, do empobrecimento do País e da desestrutura familiar, temos percebido considerável dissonância entre o discurso legal do Estado e o cuidado com o desenvolvimento da criança.

O aumento da violência contra a criança é sintoma da confusão do papel e do lugar social e jurídico da criança em relação a esse direito à liberdade, ao respeito e à dignidade. A realização concreta das leis e discursos pode contribuir para gerar crianças e adolescentes bem nutridos como sujeitos psicológicos, realizando sua inserção social plena, materializando o discurso de um estatuto que procura amparar e resguardar os direitos desses entes em formação.

Aqui, fazemos uso do conceito de nutrição psicológica, desenvolvido por Pimentel (2005), considerando que o desenvolvimento emocional e social saudável é fruto de um conjunto de aprendizagens informais (casa) e formais (escola), entendendo que a oferta de alimentos afetivos positivos é indispensável para a formação da autoestima e do autoconceito saudáveis, além da capacidade de reconhecimento do outro.

Pensamos que as transformações mundiais das sociedades ocidentais requerem novos discursos para novas práticas, pois crianças, cada vez mais cedo, são chamadas a participar da vida social de suas famílias e da construção de suas individualidades. A diminuição da autoridade do adulto sobre a criança, a facilidade de obter informações através da mídia, a proliferação da informática e a internet, que favorecem um acesso mais fácil e rápido ao mundo do adulto, pode capacitá-las a se tornarem potentes questionadores de sua realidade ou adultos incapazes do exercício da autonomia psicológica.

A criança pós-moderna é apresentada, entre outros adjetivos, na cultura popular, como um "espertinho pedante" (Steinberg e Kincheloe, 2004). Porém, toda essa rápida "evolução" tem um preço, pois, ao (não) "conseguir" lidar com tantas situações adversas e com um número maciço de informações, a criança passa a ser vista como um supergaroto que tem poderes espetaculares e competência precoce (Elkind, 2004).

Em meio às mudanças tecnológicas, educacionais, culturais e políticas que provocam tantas pressões na formação da subjetividade infantil, indagamos como a criança se percebe e a quais suportes recorre para desenvolver sua própria maneira de se adaptar a essas mudanças. No âmbito específico da violência sexual que ela sofre, interessa-nos discutir acerca das formas que o desenvolvimento emocional e social vem tomando.

\section{Violência sexual intrafamiliar}

O divórcio, pai e mãe solteiros, famílias com pais e mães trabalhando fora, jornada escolar, deveres de casa, aula de línguas, natação, informática, etc., sobrecarregam a criança, de forma que esta terá que fazer substituições em suas atividades para lidar com aquelas que eleger prioritárias. Às vezes, no meio desse tumulto, não sobra tempo para ser criança, para brincar, imaginar, elaborar, experimentar, errar, acertar, criar, enfim, desenvolver-se de forma plena, sem prejuízos para seu desenvolvimento físico e emocional. É claro que não perdemos de vista o fato de que esses fatores repercutem no desenvolvimento emocional e social das crianças, conforme a classe socio-econômica, grau de instrução do cuidador, estrutura afetiva, etc.

Em nossa pesquisa, o estudo de caso é a metodologia utilizada. Investigamos as 
repercussões psicológicas e as funções expressivas de uma adolescente que foi vítima de abuso sexual quando criança. Nossa proposta é desenvolver um estudo qualitativo acerca do desenvolvimento emocional e social da informante, de modo a contribuir para a denúncia, o diagnóstico e a intervenção precoce e preventiva da violência sexual intrafamiliar.

A partir dos anos 60, o Estado iniciou um amplo processo de reconhecimento e identificação das mais variadas formas de práticas culturais, sociais e familiares que atentavam contra os direitos da criança e do adolescente. A revelação dessas práticas tem evidenciado que a violência sobre a criança, muitas vezes, é perpetrada por adultos que são membros diretos de suas famílias, em manifestações que podem ser de ordem física, sexual, negligência, exploração sexual e prostituição, trabalho forçado, etc. (Benetti, 2002).

Araújo (2002) designa violência intrafamiliar como uma ação que ocorre na família e que envolve parentes que vivem ou não sob o mesmo teto.

No Pará, Rosa e Silva (2004) realizaram uma pesquisa na região metropolitana de Belém, e identificaram que, no período de 2000 a 2002, a maior incidência de casos de violência sexual contra crianças ocorria na família, espaço considerado seguro para as mesmas. Essa descoberta é ampliada pelas observações de Azevedo e Guerra (2002), que nos informam que morrem 5\% de jovens entre dez-catorze anos, $66 \%$ dos de doze-dezessete, vitimados pela violência intrafamiliar.

A legislação internacional e nacional em favor da criança e do adolescente, como a Declaração dos Direitos da Criança (1959), a Convenção Internacional dos Direitos da Criança (1989) e o Estatuto da Criança e do Adolescente-ECA (1990) têm contribuído para que a sociedade civil organizada combata os tipos de violência e o Estado elabore políticas públicas voltadas à proteção da criança e do adolescente.

\section{Tipologia da violência intrafamiliar e sexual}

Azevedo e Guerra (2005), consideram quatro tipos:

a) Negligência: omissão em prover as necessidades físicas e emocionais de uma criança ou adolescente. Configura-se quando os pais ou responsáveis falham em alimentar, vestir adequadamente os filhos, etc.

b) Violência física: atos que causam dor física, e não apenas dano. Também encontrada na literatura sob a denominação de síndrome, maustratos físicos e abuso físico.

Uma das manifestações mais comuns desse tipo de violência é a síndrome do bebê sacudido (shaken baby syndrome): lesões de gravidade variáveis, que acontecem quando a criança, geralmente lactente, é violentamente sacudida, na maioria das vezes pelos próprios pais, o que causa hemorragias intracranianas e intraoculares que podem levar à morte ou deixar seqüelas no aprendizado ou comportamento e causar hemiplegia, tetraplegia, convulsões, etc. (Theophilo, 2004).

c) Violência psicológica: atitudes e condutas, perante a criança, que ocasionam medo, frustração e experiência de temor quanto à própria integridade física e psicológica, ameaças verbais com conteúdo violento ou emocional. Inclui a rejeição, o não-reconhecimento da criança em sua condição de sujeito, degradação ou subvalorização da criança, expondo-a à humilhação pública e atribuindo apelidos depreciativos, terrorismo, ameaças, surras, reprimendas, castigos, isolamento, exploração.

d) Violência sexual: ato ou jogo sexual, relação hetero ou homossexual entre um ou mais adultos e uma criança ou adolescente, tendo por finalidade estimular sexualmente essa criança ou adolescente ou utilizá-lo para obter uma estimulação sobre si ou sobre outra pessoa. 
O abuso sexual é um tipo de agressão definido como o envolvimento de crianças e adolescentes dependentes e evolutivamente imaturos em atividades sexuais que eles não compreendem, para os quais não são capazes de dar consentimento informado, e que violam os tabus sexuais dos papéis familiares. Fundamentalmente, estabelece-se uma relação de poder ou controle entre a vítima e o agressor, que, não necessariamente, é uma pessoa adulta (Kristensen, Flores e Gomes, 2001).

Suas formas são: incesto, qualquer relação de caráter sexual entre um adulto e uma criança ou adolescente, entre um adolescente e uma criança, ou ainda, entre adolescentes, quando existe um laço familiar, direto ou não, ou mesmo uma mera relação de responsabilidade; estupro: do ponto de vista legal, é a situação em que ocorre penetração vaginal com uso de violência ou grave ameaça; sedução: situação em que há penetração vaginal, sem uso de violência, em adolescentes virgens de catorze a dezoito anos incompletos; atentado violento ao pudor: circunstância em que há constrangimento de alguém a praticar atos libidinosos, sem penetração vaginal, utilizando violência ou grave ameaça, sendo que, em crianças e adolescentes de até catorze anos, a violência é presumida, como no estupro; assédio sexual: propostas de contrato sexual; na maioria das vezes, há posição de poder do agente sobre a vítima, que é chantageada e ameaçada pelo agressor; exploração sexual: éa inserção de crianças e adolescentes no mercado do sexo. Inclui a pornografia infantil e a prostituição.

\section{Considerações finais}

O que é ser criança? Acreditamos que não haja uma resposta a essa pergunta. Também não somos nós, os adultos, os únicos atores responsáveis pela resposta. Através da realização de pesquisas empíricas, nas quais fazemos perguntas às crianças deixando que elas se expressem e possam fazer escolhas, talvez encontremos pistas mais sólidas para oferecer suporte psicológico e educacional e políticas públicas positivas.
É lamentável que ainda existam muitos problemas sociais que refletem um atraso nos ganhos já adquiridos pela população infantil durante $\mathrm{o}$ período pós-moderno, ou que nos fazem pensar que a infância continua sendo entendida com as mesmas concepções e olhares de dois ou três séculos atrás. Situações como a de trabalho infantil e exploração sexual devem ser cada vez mais energicamente reprimidas, para que a criança goze do direito pleno de ser criança, não apenas no sentido biológico, mas principalmente enquanto indivíduo capaz de experimentar, aprender, concluir, agir, intervir e evoluir.

A violência intrafamiliar transforma o lar em um lugar de agressão, ao invés de proteção, já que é nele que grande parte dos casos de maus-tratos acontece, o que demonstra dificuldades dentro da esfera cuidador-criança. A ocorrência de maustratos aumenta os riscos de atrasos no desenvolvimento, provoca vivências traumáticas e não atende as necessidades básicas da criança. É importante que os profissionais que atuam na área da saúde considerem a gravidade das seqüelas que a violência em forma de maus-tratos pode ocasionar no desenvolvimento, e que trabalhem atentando para identificar os casos suspeitos, de modo a intervir precocemente.

Em síntese, a violência sexual pode se apresentar sob diferentes formas, ocorrendo em contextos específicos que fazem com que seja necessário diferenciá-la. A abordagem das conseqüências do abuso sexual requer, para o seu enfrentamento, estratégias conjugadas: políticas públicas para as áreas sociais e deslocamento de recursos para o capital produtivo a fim de criar emprego e renda; tratamento interdisciplinar dos sistemas familiares ou rede de cuidadores que envolvam o agente e a vítima da violência.

É indispensável promovermos a ruptura com a representação desqualificadora de que a criança seja alguém incompleto. É recebendo compreensão, respeito e valorização do seu potencial e limite para crescer e enfrentar os dilemas cotidianos que a criança faz e refaz os alicerces de sua identidade e participa da construção da história e da cultura de seu tempo (Andrade, 1998). 
ANDRADE, A. N. A Criança na Sociedade Contemporânea: do ‘ainda não' ao Cidadão em Exercício. Psicologia: Reflexão e Crítica, vol. 11, ㄲo 1, pp.161-174, 1998.

ARAÚJO, M. F. Violência e Abuso Sexual na Família. Psicologia em Estudo, v.7, ㄲo 2, pp. 3-11, jul./dez. 2002.

AZEVEDO, M. A; GUERRA, U. N. A. Infância e Violência Doméstica. São Paulo: LACRI-USP, v. 01, 2002.

(orgs). Infância e Violência Doméstica: Fronteiras do Conhecimento. 4ª ed. São Paulo: Cortez, 2005.

BARROS, D.D.; GHIRARDI, M.I.G.; LOPES, R.E. Terapia Ocupacional Social. Revista de Terapia Ocupacional da Universidade de São Paulo, São Paulo, v. 13, no 3, pp. 95-103, 2002.

BELLO, A. A. Fenomenologia e Ciências Humanas. Bauru, SP: EdusC, 2004

BENETTI, S. P. C. Maus-tratos da Criança: Abordagem Preventiva. In: Hutz, C. S. Situaç̃es de Risco e Vulnerabilidade na Infância e na Adolescência: Aspectos Teóricos e Estratégias de Intervenção. São Paulo: Casa do Psicólogo, 2002, pp. 132-150.

BOARINI, M. L.; BORGES, R. F. Demanda Infantil por Serviços de Saúde Mental. In: A Demanda Infantil à Saúde Mental: Reflexo de uma Crise? Monografia, Universidade Estadual de Maringá, 1996

CASTRO, L. R. A Infância e seus Destinos no Contemporâneo. Psicologia em Revista, Belo Horizonte, v.8, no 11, pp. 47-85, jun. 2002.

DIAS, D. Pacto vai enfrentar violência sexual. Diário do Pará, Belém, 13 mai. 2007. Cidades, p. 4.

FERREIRA, A.B.H. Novo dicionário Aurélio século XXI. Versão eletrônica 3.0. Lexikon informática Ltda, 1999.

ELKIND, D. Sem Tempo para Ser Criança: a Infância Estressada. $3^{3}$ ed. Porto Alegre: Artmed, 2004.

JORGE, R. C. Psicoterapia Ocupacional: História de um Desenvolvimento. Belo Horizonte: Gesto, 1995.

HEYWOOD, C. Uma História da Infância. Porto Alegre: ArtMed, 2004.

HARVEY, D. Condição Pós-Moderna. $13^{3}$. Ed. São Paulo: Loyola, 2004.

HAZEU, M. Direitos Sexuais da Criança e Adolescente: uma Visão Interdisciplinar para o Enfrentamento da Violência Sexual contra Crianças e Adolescentes. Movimento República de Emaús, Belém: Sagrada Família, 2004.

\section{Adelma Pimentel}

Lucivaldo da Silva Araújo
ando em Psicologia (UFPA).

CEP: 66093-090. Tel.: (91) 8867-6177 / (91) 8866-6178

l.com; cacaoaraujo@yahoo.com.br; adelmapi@ufpa.br.
KRISTENSEN, C. H.; FLORES, R. Z.; GOMES, W. B. Revelar ou não Revelar: uma Abordagem Fenomenológica do Abuso Sexual em Meninos. In: Buins, M. A. T; Holanda, A. F. Psicologia e Pesquisa Fenomenológica. São Paulo: Ômega, 2001.

LIBERMAN, F. Danças em Terapia Ocupacional. São Paulo: Summus, 1998.

MAUAD, A. M. A Vida das Crianças de Elite durante o Império. In: Del Priore, M. História das Crianças no Brasil. 4aํ ed. São Paulo: Contexto, 2004, pp.137-176.

MEDEIROS, M. H. R. Terapia Ocupacional: um Enfoque Epistemológico e Social. São Carlos: EdUFSCAR, 2003.

MINISTÉRIO DA SAÚDE. Fundamentos Técnico-Científicos e Orientações Práticas para o Acompanhamento do Crescimento e Desenvolvimento. Parte 2: Desenvolvimento. Março de 2001.

NASCIMENTO, B. Loucura, Trabalho e Ordem: o Uso do Trabalho e da Ocupação em Instituições Psiquiátricas. São Paulo, Programa de Estudos Pós-graduados em Ciências Sociais da PUC - SP. Dissertação de Mestrado, 1991

PERLS, F. S. Yo, Hambre y Agresión. México, Fondo de Cultura Económica, 1975.

PIMENTEL, A. Psicodiagnóstico em Gestalt-terapia. São Paulo: Summus, 2003.

Nutrição Psicológica: Desenvolvimento Emocional e Social. SP: Summus, 2005.

ROSA, S.; SILVA, S. M. Proteção versus Agressão: Violência Doméstica como a Grande Contradição Familiar. In: Movimento República de Emaús. Violência contra Crianças e Adolescentes em Abaetetuba, Belém, Cametá e Paragominas. Belém: Centro de Defesa da Criança e do Adolescente, 2004, pp. 20-24.

STEINBERG, S. R.; KINCHELOE, J. L (org.). Cultura Infantil: a Construção Corporativa da Infância. $2^{\underline{a}}$ ed. Rio de Janeiro: Civilização Brasileira, 2004.

STEIN, E. Epistemologia e Crítica da Modernidade. $3^{3}$ ed. ljúi-RS: Unijuí. 2001.

STEINER, S. H. F. A Violência contra a Criança no Direito Positivo. In: Steiner, M. H. F. (org.) Quando a Criança não Tem Vez: Violência e Desamor. São Paulo: Pioneira, 1986. p. 127-133.

THEOPHILO, R. Violência psicofísica na criança e no adolescente. Disponível em: http://www.psicologia.org.br/internacional/ ap26.htm. Acesso em: 15 mai. 2004.
Referências 